\title{
FORMAÇÃO DE PROFESSORAS/ES E LIDERANÇAS QUILOMBOLAS DO SAPE DO NORTE-CONCEIÇÃO DA BARRA-ES: O QUE NOS DIZEM?
}

\author{
FORMACIÓN DE PROFESORES / ES Y LIDERAZGOS QUILOMBOLES DEL SAPÉ DO \\ NORTE-CONCEIÇÃO DE BARRA-ES: ¿QUÉ NOS DICEN?
}

\author{
TRAINING OF TEACHERS / ES AND QUILOMBOL LEADERSHIPS OF THE SAPÉ DO \\ NORTH-CONCEIÇÃO OF BARRA-ES: WHAT DO WE TELL?
}

\section{Doi: 10.22481/rbba.v1i02.7785}

\begin{abstract}
RESUMO
Esse artigo apresenta um recorte da pesquisa intitulada: "Entrelaçando Saberes e Narrativas: Formação de Professoras/es e Lideranças Quilombolas em Conceição da Barra - ES", do Mestrado Profissional em Educação da Universidade Federal do Espírito Santo, em fase de conclusão. O estudo buscou estudar a formação de professoras/es e lideranças quilombolas. Por meio da intervenção social (Formação), priorizamos a promoção de ações pedagógicas antirracistas, valorizando as narrativas e saberes das comunidades. Apresentaremos, nesse artigo, o diálogo do espaço formativo como locus da pesquisa. Os principais referenciais teóricos desse estudo são: Gomes $(2003 ; 2005)$ que aponta a necessidade de estratégias para implementações de políticas afirmativas na Educação, Santos (2007; 2010b) que destaca a necessidade de valorização de histórias outras rompendo com a visão única de conhecimento. A metodologia da pesquisa-ação oportunizou o movimento de intervenção social a partir das problemáticas levantadas pelos participantes. As narrativas colhidas mostraram desafios que impactam diretamente a educação quilombola como: o racismo estrutural, os problemas ambientais que envolvem os territórios atualmente tomados pela monocultura de eucaliptos e a falta de formação para a educação quilombola que considere as relações étnico-raciais.
\end{abstract}

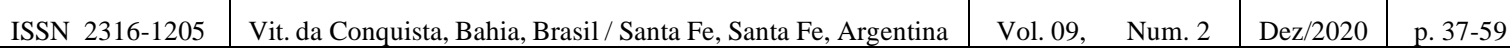


Palavras-Chave: Formação de Professores/as quilombolas; Relações Étnico-Raciais; Educação antirracista.

\title{
RESUMEN
}

Este artículo presenta un extracto de la investigación titulada: "Entrelazando conocimientos y narrativas: Formación de profesores / líderes quilombolas en Conceição da Barra - ES", de la Maestría Profesional en Educación de la Universidad Federal de Espírito Santo, en fase de conclusión. El estudio buscó estudiar la formación de maestros / líderes quilombolas. A través de la intervención social (Capacitación), priorizamos la promoción de acciones pedagógicas antirracistas, valorando las narrativas y conocimientos de las comunidades. En este artículo presentaremos el diálogo del espacio formativo como locus de la investigación. Los principales referentes teóricos de este estudio son: Gomes (2003; 2005), quien señala la necesidad de estrategias para la implementación de políticas afirmativas en Educación, Santos (2007; 2010b) quien destaca la necesidad de valorar historias además de romper con la visión única del conocimiento. La metodología de investigación-acción brindó una oportunidad para el movimiento de intervención social basada en los temas planteados por los participantes. Las narrativas recopiladas mostraron desafíos que impactan directamente la educación quilombola, tales como: el racismo estructural, los problemas ambientales que rodean los territorios actualmente ocupados por el monocultivo de eucaliptos y la falta de formación para una educación quilombola que considere las relaciones étnico-raciales.

Palabras clave: Formación docente quilombola; Relaciones étnico-raciales; Educación antirracista.

\begin{abstract}
This article presents an excerpt of the research entitled: "Interweaving Knowledge and Narratives: Training of Quilombola Teachers / Leaders in Conceição da Barra - ES", from the Professional Master in Education at the Federal University of Espírito Santo, in the conclusion phase. The study sought to study the formation of quilombola teachers / leaders. Through social intervention (Training), we prioritize the promotion of anti-racist pedagogical actions, valuing the communities' narratives and knowledge. In this article, we will present the dialogue of the formative space as the locus of the research. The main theoretical references of this study are: Gomes $(2003 ; 2005)$, who points out the need for strategies for the implementation of affirmative policies in Education, Santos $(2007 ; 2010 b)$ who highlights the need to value stories other than breaking with the unique view of knowledge. The action research methodology provided an opportunity for the social intervention movement based on the issues raised by the participants. The collected narratives showed challenges that directly impact quilombola education, such as: structural racism, the environmental problems that surround the territories currently occupied by monoculture of eucalyptus and
\end{abstract}


SAPÊ DO NORTE-CONCEIÇÃO DA BARRA-ES: O QUE NOS DIZEM?

the lack of training for quilombola education that considers ethnicracial relations.

Keywords: Teacher Training quilombolas; Ethnic-Racial Relations; Anti-racist education.

\section{Apresentando o estudo}

Esse artigo apresenta um recorte da pesquisa-ação intitulada: "Entrelaçando Saberes e Narrativas: Formação de Professoras/es e Lideranças Quilombolas em Conceição da Barra ES”. Trata-se de uma pesquisa em fase final realizada no Mestrado Profissional em Educação da Universidade Federal do Espírito Santo. Consiste em estudos sobre formação de professores/as e lideranças quilombolas desenvolvidos na região do Sapê do Norte-Conceição da Barra, no Estado do Espírito Santo-Brasil. É uma pesquisa engajada com os movimentos sociais e necessidades advindas das lideranças das comunidades (em especial, mestres e mestras jongueiras) que, desde 2012, sinalizaram nas oficinas de salvaguardas ${ }^{1}$ das culturas tradicionais que a formação de professoras/es quilombolas se fazia necessária, pois acreditam que a formação é importante para a valorização das culturas das comunidades tradicionais e implementação das leis 10.639/03 e 11. 645/08.

Esse texto justifica-se na necessidade de divulgação dos estudos relativos à formação de professoras/es e lideranças das comunidades tradicionais rurais quilombolas tendo em vista que ainda são poucas as pesquisas sobre formação de professoras/es da região supracitada.

Para tanto, foi considerado um pequeno recorte de nossa pesquisa buscando refletir sobre as narrativas das professoras/es e lideranças das comunidades que foram envolvidas nas ações da formação de professoras/es quilombolas e lideranças. A pesquisa teve, em seus objetivos gerais, o propósito de estudar o campo de formação de professores/as e lideranças quilombolas a partir das experiências que foram interfaces do processo formativo (intervenção da pesquisa) na região de Sapê do Norte em Conceição da Barra - ES. Dessa forma, esse artigo enfatizará a composição da formação de professoras/es quilombolas bem como irá refletir sobre o que nos dizem essas/es profissionais.

O texto apresenta a região da pesquisa e um breve histórico territorial, o locus da intervenção social. A escuta ativa foi uma das estratégias na recepção de coletas de dados, além das transcrições dos encontros formativos, memoriais, projetos escritos e atividades individuais 
SAPÊ DO NORTE-CONCEIÇÃO DA BARRA-ES: O QUE NOS DIZEM?

e coletivas. Sua base teórica está, principalmente, em Gomes $(2003 ; 2005)$ e Santos (2007; 2010b).

A pesquisa em tela trouxe algumas questões para o estudo. A intenção era desvelar como são realizadas as formações de professoras/es quilombolas, compreender como as leis 10.639/03 e 11.645/08 são implementadas e quais os desafios que acometem a formação de profissionais da educação quilombola da região. Estas leis apontam a obrigatoriedade do ensino de conteúdos de História e Cultura Africana nos currículos da Educação Básica. A LDB (Lei de Diretrizes e Bases da Educação) no 9394/96, alterada o art. 26A, pela lei 10.639/03, traz a obrigatoriedade do ensino da História e Cultura Afro-Brasileira nos estabelecimentos de ensino fundamental e médio das escolas oficiais, públicas e privadas. A lei 11.645/08, que também altera a Lei 9.394, de 20 de dezembro de 1996, estabelece as diretrizes e bases da educação nacional para incluir, no currículo oficial da rede de ensino, a obrigatoriedade da temática "História e Cultura Afro-Brasileira e Indígena".

As reflexões foram traçadas dentro da formação de professoras/es e os objetivos centrais para o processo de Intervenção social foram baseados numa educação antirracista, reconhecendo a importância das narrativas das comunidades nas práticas pedagógicas; incentivando o uso de recursos e suportes pedagógicos que ampliasse as possibilidades de trabalho como: o uso da sequência didática, quadrinhos, tirinhas e literaturas africanas e afrobrasileira, fazendo o entrelaçar dessas histórias com as contadas pela comunidade quilombola, além de subsidiar dados qualitativos de análise para a pesquisa.

\section{A região do estudo e formação}

A pesquisa foi desenvolvida com professoras/es e lideranças das comunidades quilombolas da região do Sapê do Norte. Essa região ocupa uma área entre São Mateus e Conceição da Barra no Estado do Espírito Santo-Brasil, mas as/os participantes envolvidas/os pertencem ao município de Conceição da Barra. Esse território já foi ocupado por cerca de 12 mil famílias distribuídas em quase 100 comunidades quilombolas.

No entanto, as comunidades foram sendo expulsas de seus territórios durante todo o percurso histórico brasileiro. Destaca-se o processo de colonização em solo capixaba (na tentativa de embranquecimento da população) patrocinado pelo Estado e período do regime militar. Em ambos os movimentos, as comunidades foram violentadas e perseguidas para que 
SAPÊ DO NORTE-CONCEIÇÃO DA BARRA-ES: O QUE NOS DIZEM?

saíssem de seus territórios visto que, assim, o Estado teria a terra para doação à "nova população" branca e os negros/negras quilombolas foram abandonados sem qualquer possibilidade de sobrevivência ou política pública positiva, tendo em vista que, para a população quilombola, o território, a terra é meio de sobrevivência dos grupos étnicos, manutenção dos núcleos familiares. A terra, para as comunidades rurais quilombolas, não tem valor de mercadoria como a visão de grandes empresas exploradoras dessa região, Ferreira (2002, p.41) relata que:

É sobre a terra que se faz o trabalho que constrói o patrimônio da família. Neste sentido, as sociedades camponesas ou tradicionais estariam estruturadas neste tripé terra, família e trabalho, categorias relacionadas entre si e vistas como valores vinculados a princípios organizatórios próprios.

$\mathrm{Na}$ década de 80, durante a corrida pelo famigerado "progresso", as comunidades sentiram a pressão das grandes empresas e latifúndio que provocaram destruição das matas da região para construção de pastos (criação de bois), plantio de cana-de-açúcar e monocultura de eucalipto.

Ferreira (2002) acredita que o capitalismo vê essa luta como guerra e se posiciona muito bem "engatilhado" via desmatamento, envenenamento do solo, córregos e rios, perseguições de lideranças das comunidades, articulações políticas na sociedade para o desmantelamento ou negação de políticas públicas para esses territórios. Ferreira (2002) destaca, em suas pesquisas, como as empresas agiram desde a década de 70 para tomar as terras dos quilombolas do Sapê do Norte. A pesquisadora fez a escuta dos mais velhos. Eles narraram as várias estratégias utilizadas desde a demarcação "forjada à falsas informações, e até mesmo ameaças por meio do Tenente Merçon, que utilizava da sua patente para intimidar os povos quilombolas, forçandoos a vender ou desocupar a terra.

As violações de direitos aos povos quilombolas, não só nessa região, mas em todo país, exigiram dessa população a organização em movimentos sociais para debater e exigir posicionamento do Estado no que diz respeito à regularização e titularidades desses territórios. Ainda que tardiamente, essa agenda foi constituída a partir da Constituição Federal de 1988 em que o artigo 68 do (ADCT) - Ato das Disposições Constitucionais Transitórias, reconheceu as propriedades das terras onde viviam os povos quilombolas. Desse modo, o Estado passou a ter a obrigatoriedade da emissão de títulos conforme redação: “Art.68. Aos remanescentes das 
comunidades dos quilombolas que estejam ocupando suas terras é reconhecida a propriedade definitiva, devendo o Estado demitir-lhes os títulos respectivos" (BRASIL,1988).

Leite $(1999$, p.135) afirma que o quilombo deve ser visto como um espaço mantido por gerações e não pode ser reconhecido apenas como um passado a ser rememorado. Essa concepção realça novas situações surgidas na pauta política como: as lutas dos afrodescendentes, a militância, os partidos políticos que foram chamados a definir o que de fato vem a ser o quilombo e quem são os quilombolas. Leite $(1999$, p.136) ainda destaca:

O artigo 68 traduz uma formulação sugestiva, ao se referir aos remanescentes das comunidades dos quilombos. Impõe sobre o próprio conceito de quilombo, ou quilombola, ou remanescente, a possibilidade de se chegar a identificar um direito e, consequentemente, os sujeitos deste direito.

Sabendo do histórico da Região da pesquisa, essa perspectiva possibilita pensar os remanescentes de quilombos do Sapê do Norte, em conformidade com o que nos diz a Associação Brasileira de Antropologia (ABA) (1997, p.5):

[...] a categoria 'remanescentes de quilombos' deve compreender todos os grupos que desenvolveram práticas de resistência na manutenção e reprodução de seus modos de vida característicos num determinado lugar, cuja identidade se define por uma referência histórica comum, construída a partir de vivências e valores partilhados. Nesse sentido, eles se constituem como 'grupos étnicos', isto é, um tipo organizacional que confere pertencimento através de normas e meios empregados para indicar afiliação ou exclusão, cuja territorialidade é caracterizada pelo 'uso comum', pela 'sazonalidade das atividades agrícolas, extrativistas e outras e por uma ocupação do espaço que teria por base os laços de parentesco e vizinhança, assentados em relações de solidariedade e reciprocidade'.

Essas comunidades ainda sofrem a violação de direitos e descaso do poder público frente às problemáticas causadas por esse histórico de expulsão dos territórios, devastação da vegetação local que acarretou, principalmente, o desaparecimento dos rios e lagoas dos territórios. As narrativas coletadas para nosso trabalho foram feitas com autorização prévia de todos/as participantes da pesquisa. Utilizamos variados instrumentos: gravações das formações, respostas de atividades formativas, memoriais e escritas de projetos pedagógicos. Ao analisarmos as respostas a esses dados, percebemos a confirmação dos fatores históricos aliados às pesquisas acadêmicas, pois consolidam o contexto histórico presente nas memórias da 
SAPÊ DO NORTE-CONCEIÇÃO DA BARRA-ES: O QUE NOS DIZEM?

população desse território. Ao descrever suas memórias em tempo de escola, a professora Josineia entrelaça sua vivência com todo o contexto histórico citado. Ela destaca:

\begin{abstract}
Nessa época as comunidades ainda não eram reconhecidas como comunidade quilombola para o governo. Fomos muito massacrados pelas empresas com a destruição da natureza que era a nossa riqueza. A natureza era considerada a nossa mãe por ser nossa a sobrevivência. Isso nos deixou muito triste. $\mathrm{Na}$ época, quando cursava do $1^{\circ}$ ao ensino médio, o ensinamento da escola era que os negros eram escravos e que vieram da África para ser escravizados, eram preguiçosos e ladrões e para os colegas eram povos relaxados, porcos, cabelos de pinxaim e pretos só isso que eu aprendi na escola. Éramos povos enganados pelos políticos e pelas grandes empresas. (Professora e liderança Josineia, Conceição da Barra-2019).
\end{abstract}

A narrativa da professora Josineia aponta muitas reflexões. A tristeza de ver seu território devastado pela monocultura de eucalipto, a angústia de ter que "aprender" na escola que os povos de sua etnia eram considerados "preguiçosos, ladrões e relaxados". Todas essas questões perpassam o pensamento racista forjados na sociedade brasileira, construído no viés das teorias racistas ${ }^{i}$ que subjugou a população negra como "raça inferior" e selecionou a "raça branca" como superior, deslegitimando toda história, religiões, ciências, culturas, saberes e conhecimentos dessa população.

Gomes (2003) aponta que o corpo é um terreno social conflitivo, pois envolve as relações de poder construídas e respaldadas no racismo. Esse corpo é simbolicamente tocado, julgado como inferior. Ressalta que, em torno da "manipulação do corpo e do cabelo do negro, existe uma vasta história. Uma história ancestral e uma memória".

Ao longo da história, o corpo se tornou um emblema étnico e sua manipulação tornou-se uma característica cultural marcante para diferentes povos. Ele é um símbolo explorado nas relações de poder e de dominação para classificar e hierarquizar grupos diferentes. O corpo é uma linguagem e a cultura escolheu algumas de suas partes como principais veículos de comunicação. O cabelo é uma delas (GOMES, 2003, p. 174).

Cabe ressaltar que a mentalidade do povo brasileiro ainda opera na mesma ideologia na qual os tentáculos dessas teorias raciais ramificam, consolidam-se, reinventam-se, sempre na mesma ótica cuja tentativa é inferiorizar o jeito de ser, de estar, de viver, de pensar, de sentir-se negro e negra no Brasil. Sentimo-nos aguçadas em pensar a formação de professoras/es 
quilombolas e suas especificidades intervindo diretamente nos desafios apontados pelo grupo cuja maioria de componentes é autodeclarada negra em nossa pesquisa. $\mathrm{O}$ fato de serem negras/os e quilombolas marca esses sujeitos nas agruras históricas do racismo. Racismo que não se inicia agora, nem tão pouco tem data para acabar, tendo em vista o histórico secular de racismo estrutural de nossa sociedade.

No entanto, os movimentos sociais não estão dormentes e mobilizam-se para outros paradigmas diferentes desses em que os dominantes têm cunho voltado ao epistemicídio que, atrelado ao capitalismo, figura-se nas empresas de eucaliptos que ainda "massacram" a população dos territórios das/os participantes da pesquisa-ação.

\section{A formação como lócus de pesquisa: os caminhos possíveis de intervenção social}

A metodologia de nosso estudo utilizou-se da pesquisa ação e propôs uma intervenção social na qual se desenvolveu um plano de formação de professores/as e lideranças. Esta formação foi oferecida em consonância com demandas prévias dos movimentos sociais. Foi planejada a teia formativa de um curso que aconteceu em 10 módulos presenciais de 8 horas cada encontro e 40 horas divididas em 3 módulos de orientações de projetos a serem desenvolvidos nas comunidades (com relatórios postados na plataforma digital, Sala de aula CLASSROOM), totalizando 120 horas de ações formativas.

Os memoriais e projetos desenvolvidos frutos dessa formação foram elaborados na finalidade de visibilizar os saberes e narrativas do quilombo nas ações nas comunidades e, posteriormente, será publicado de modo coletivo via e-book. Para a inscrição no curso formativo, solicitamos às interessadas/os que respondessem a algumas questões, entre elas: "Por que você deseja participar da formação dessa pesquisa-ação"? 


\begin{tabular}{|c|c|c|}
\hline $\begin{array}{c}\text { "Por que você deseja participar da formação dessa } \\
\text { pesquisa-ação"? }\end{array}$ & Quantidade & Percentual \\
\hline $\begin{array}{l}\text { Porque precisamos muito entender e fortalecer as leis } \\
10.639 / 03 \text { e 11.645/08, no município, sobretudofazendo um } \\
\text { trabalho sério nas escolas. Buscar mais conhecimentos para } \\
\text { trabalhar em sala de aula. Expandir a cultura e combater o } \\
\text { racismo e a segregação. Para enriquecimento da prática } \\
\text { pedagógica e contribuir com os saberes. Para fortalecer as } \\
\text { minhas raízes africanas. } \\
\text { (Obs:respostas agrupadas por eixos similares) }\end{array}$ & 28 & $96,7 \%$ \\
\hline $\begin{array}{l}\text { Para adquirir conhecimento. } \\
\text { Porque tenho um sonho de trabalhar com a educação das } \\
\text { crianças da comunidade. }\end{array}$ & 1 & $0,74 \%$ \\
\hline $\begin{array}{l}\text { Uma área pela qual sou apaixonado ou Porque o } \\
\text { tema é interessante. }\end{array}$ & 2 & $0,37 \%$ \\
\hline Atuo na área de Filosofia. & 1 & $0,74 \%$ \\
\hline $\begin{array}{l}\text { Porque tenho um sonho de trabalhar com as crianças da } \\
\text { minha comunidade. }\end{array}$ & 1 & $0,37 \%$ \\
\hline $\begin{array}{l}\text { Porque acrescentará no meu curriculum, pois estou } \\
\text { cursando licenciatura em educação do campo. }\end{array}$ & 2 & $\mathbf{1 0 0 \%}$ \\
\hline Total & $\mathbf{3 7}$ & $0,74 \%$ \\
\hline
\end{tabular}

Tabela 1 - Respostas recolhidas em 37 formulários de inscrições:

Fonte: elaborado pela autora-2019

Os resultados vistos apontaram que grande maioria, 96,7\% dos conteúdos das respostas, estava atrelada à vontade de entender e fortalecer as leis 10.639/03 e 11.645/08 no município, na pretensão de buscar conhecimentos para trabalhar as questões étnico - raciais em sala de aula e enriquecimento da prática pedagógica. Nos registros escritos, ainda foram apontados o desejo de fortalecer as raízes e saberes quilombolas.

Os anseios citados não divergem das demandas evidenciadas na carta de propostas e diretrizes apresentadas em 2012, no II Encontro de jongueiros do ES cujos objetivos eram discutir políticas de salvaguardas das culturas tradicionais, ou seja, a hipótese, por hora, é que são demandas antigas, ainda não superadas na formação desses participantes, professores/as e lideranças. Para que a formação se caracterizasse como necessidades fidedignas desses atores sociais, o processo de intervenção (via formação) manteve-se atento à escuta das lideranças e professoras/es. 
SAPÊ DO NORTE-CONCEIÇÃO DA BARRA-ES: O QUE NOS DIZEM?

\section{A escuta ativa no processo de intervenção}

A escuta ativa foi parte importante do método desse trabalho, pois as/os participantes tinham muito a nos dizer e a nós coube o papel fundamental da "escuta". Nas rodas de conversas formativas, sempre lançávamos questões disparadoras e dialogávamos sobre a temática escolhida, antecipadamente, pelo grupo. Eram momentos aliados a estudos teóricos e oficinas. A metodologia de escutar fez parte de todos os encontros, qualificando-os e fomentando estratégias seguintes, na perspectiva de atender o que o grupo apresentava como problemáticas, saberes e memórias de seus territórios. Utilizamos as reflexões de Santos (2018) que destaca a importância de aprender a "escutar" e valorizar a oralidade. Segundo ele, vivemos no mundo em que a literatura ocidental e a escrita não valorizaram as epistemologias dos países colonizados. Estes povos tiveram suas ciências e todos conhecimentos da história apagados ou invisibilizados.

Santos (2018) afirma, ainda, que o escutar é diferente de "ouvir", tendo em vista que "escutar" é abrir-me a outros, numa escuta profunda, de modo que as pessoas envolvidas promovam o diálogo entre os diferentes modelos de conhecimentos. A formação como intervenção social foi garantida e construída no coletivo de participantes e parceiros/as do Núcleo de Estudos Afro-Brasileiros - NEAB-UFES, Secretaria de Educação via Comissão de Estudos das Relações Étnico-Raciais-CEAFRO, Secretaria de Cultura, Programa de Mestrado Profissional em Educação-UFES e Coordenação Nacional de Articulação das Comunidades Negras Rurais Quilombolas - CONAQ. No primeiro encontro para organização da formação, o grupo apresentou as demandas formativas. Ressalta-se que todos os temas apresentados pelo grupo consideraram as Diretrizes Curriculares Nacionais para a Educação Escolar Quilombola na Educação Básica - Resolução nº 8, de 20 de novembro de 2012, conforme aponta o parágrafo primeiro:

$\S 1^{\circ}$ A Educação Escolar Quilombola na Educação Básica:

I - Organiza precipuamente [principalmente] o ensino ministrado nas instituições educacionais fundamentando-se, informando-se e alimentandose:
a) da memória coletiva;
b) das línguas reminiscentes;
c) dos marcos civilizatórios;
d) das práticas culturais;
e) das tecnologias e formas de produção do trabalho;
f) dos acervos e repertórios orais; 
g) dos festejos, usos, tradições e demais elementos que conformam o patrimônio cultural das comunidades de todo o país;

h) da territorialidade. (BRASIL. 2012)

O grupo destacou a necessidade de inclusão dessas temáticas nas formações de professoras/es da educação quilombola, pois são os docentes os responsáveis (via currículo e suas práticas pedagógicas) que farão essa etapa do ensino escolarizado. Ressaltamos que a aplicação das leis 10.639/03 e 11.645/08 que preconizam a obrigatoriedade da inclusão da temática "História e Cultura Afro-Brasileira e Indígena" se constituem como direito de aprendizagem, isto é, toda criança tem o direito de conhecer as histórias e culturas africanas e afro-brasileiras. As narrativas e saberes quilombolas se constituem como direitos e contêm elementos essenciais para a compreensão do processo histórico, cultural, político e econômico que envolvem os territórios.

É justo que se queira dialogar e aprofundar essas discussões, pois já sabem que os conhecimentos das comunidades precisam adentrar os conhecimentos da /na escola. É preciso desvendar os estudos sobre quilombos, articulação social e política dos mesmos, modo de ver e sentir a terra e seus territórios, a valorização das memórias, a ancestralidade, a importância da oralidade, os desafios do mundo do trabalho e culturas, ou seja, são desafios que requerem organização coletiva, subsídios de outras políticas públicas como, por exemplo, formação de professores/as a fim de garantir que essas diretrizes e leis se consolidem de fato. Perguntamos aos participantes como o município realizava as formações de professoras/es quilombolas, de quais cursos elas/es já tinham participado que consideraram as temáticas étnico-raciais. As narrativas trouxeram considerações reflexivas sobre a formação de professoras/es da educação quilombola da região:

[...] Nesse curso, as questões foram contempladas, mas em outras formações tipo: PNAIC, não recordo essas questões contempladas. [...] Não tenho nenhum curso voltado para essa temática (Professora Soraya-2019)

[...] Não. Participei do Escola da Terra dentre outros em que eu venho participando, visualizo que estas formações que o município oferece ainda não oferece... não contempla para esses professores. (Professora Selma -2019)

[...] Infelizmente ainda não. Essa é a primeira formação para professores quilombolas em que eu participo. Nos anos anteriores já aconteceram duas formações. (Chayeny) assessora pedagógica -SEME-CB. 2019)

[...] Agora com o curso: "Narrativas e Histórias africanas e afro-brasileiras", de mais, não teve essas formações. (Professora Josineia)

[...]. As formações acontecem em conjunto com os professores do centro, os temas são abordados de modos gerais. (Professora Geanis) 
A resolução $N^{o} 8$ de 20/11/2012 que implementa as Diretrizes Curriculares Nacionais para a Educação Escolar Quilombola na Educação Básica, aponta que a educação escolar quilombola tenha pedagogia própria. O artigo 32 ressalta que "O projeto político-pedagógico da Educação Escolar Quilombola deverá estar intrinsecamente relacionado com a realidade histórica, regional, política, sociocultural e econômica das comunidades quilombolas". (BRASIL,2012).

Esta mesma resolução explicita como a formação continuada deve ser ofertada não só para os/as docentes das escolas quilombolas, mas também para docentes das escolas que recebem estudantes quilombolas. A partir dessas e outras narrativas e reflexões no grupo, levantamos a hipótese de que as políticas de formação docente para a Educação Quilombola carecem de espaços-tempos formativos que contemplem as especificidades da Educação quilombola em conformidade com a resolução supracitada que, em seu art.53, dispõe a organização das formações continuadas para professoras/es das escolas quilombolas.

Outra questão levantada ao longo dos debates formativos apontou um olhar específico nas discussões sobre os desafios para se trabalhar as questões das relações afro-brasileiras nas escolas das comunidades. Algumas professoras e lideranças destacaram:

[...] Vejo que o desafio é trabalhar a questão racial no município, principalmente nas escolas, trabalhar a lei 10.639-03 dentro do município, até mesmo a formação do professor para trabalhar a questão e incluir no currículo escolar. (Professora e liderança (Professora Geanis Cosme,2019)

[...] $1^{\mathrm{o}}$ Dificuldade e carência de literaturas que abordem a temática afrodescendente, digo, carência no acervo municipal. $2^{\circ} \mathrm{A}$ visão de muitos educadores em tratar as crianças negras como coitadas, dignas de pena e caridade. (Professora Marcia, 2019)

Essas narrativas nos apontam e se aliam aos desafios que atrelam formação de professores/as, necessidade dos/as gestores/as municipais de construírem caminhos possíveis para a formação de professoras/es. Necessita-se de recursos financeiros para compra de materiais, literaturas e demais materiais de ordem formativa a fim de se possibilitar a implementação das questões das relações étnico-raciais e, assim, contemplar essas/es profissionais da educação quilombola e suas especificidades. 
SAPÊ DO NORTE-CONCEIÇÃO DA BARRA-ES: O QUE NOS DIZEM?

\section{Entrelaçando teóricos}

Para o desenvolvimento desse trabalho, entrelaçamos os diálogos teóricos com Santos (2007; 2010b) que nos aponta a necessidade de valorização de histórias outras, rompendo com a visão única de conhecimento e Gomes $(2003 ; 2005)$ que destaca a necessidade de estratégias e ações para implementações de políticas afirmativas na Educação, bem como a valorização do histórico do movimento negro educador e formação de professores/as.

Compreendemos a educação quilombola por meio das Diretrizes Curriculares Nacionais para a Educação Escolar Quilombola, pois essas nos apontam as considerações que devemos ter sobre as realidades dos povos quilombolas e alguns aspectos que precisam ser considerados como as concepções de quilombo, território, lutas da comunidade quilombola, a relação entre quilombos e trabalho, cultura e ancestralidade africana, os avanços e limites do direito dos quilombolas na legislação brasileira e a educação escolar quilombola.

A educação quilombola teve grandes avanços a partir da criação das Diretrizes Curriculares. Esses avanços foram em relação ao material didático e alimentação, no entanto, segundo Carril (2017, p. 14), ainda se revela que "são muitas as inseguranças presentes na educação quilombola, envolvendo as condições dos estabelecimentos escolares, o uso de recursos didáticos apropriados e a formação docente".

Gomes aponta que as articulações dos saberes escolares e não escolares, entre culturas, identidade negra e educação precisam ser inseridas nos processos formativos. A pesquisadora apresenta algumas questões a se considerar:

A articulação entre a produção teórica educacional sobre o negro e a produção que tem sido realizada por diferentes áreas do conhecimento sobre a mesma temática poderá nos ajudar a descobrir novas dimensões da realidade racial brasileira?

O conhecimento dessas dimensões não poderá ser incorporado como mais uma competência dos educadores nos seus processos de formação? Sem dúvida, os questionamentos acima nos mostram que essa não é uma tarefa fácil. Para realizá-la, será preciso entender e considerar a importância da articulação entre cultura, identidade negra e educação. Uma articulação que se dá nos processos educativos escolares e não-escolares (GOMES, 2003, p.169).

Ressaltamos que as articulações cultura, identidades e educação nos territórios quilombolas atrelam-se às memórias individuais e coletivas, histórias e saberes ancestrais que 
SAPÊ DO NORTE-CONCEIÇÃO DA BARRA-ES: O QUE NOS DIZEM?

precisam estar no currículo escolar, conforme trata a resolução $n^{0} 8$, de 20 de novembro de 2012, que define as Diretrizes Curriculares Nacionais para a Educação Escolar Quilombola na Educação Básica.

Esta resolução traz, em seus pontos principais, a necessidade de fundamentar uma educação que considere: a) a memória coletiva; b) as línguas reminiscentes; c) os marcos civilizatórios; d) as práticas culturais; e) as tecnologias e formas de produção do trabalho; f) os acervos e repertórios orais; g) os festejos, usos, tradições e demais elementos que conformam o patrimônio cultural das comunidades quilombolas de todo o país; $h$ ) a territorialidade.

Segundo Le Goff (1990, p.411), “A memória, onde cresce a história, que por sua vez a alimenta, procura salvar o passado para servir o presente e o futuro. Devemos trabalhar de forma a que a memória coletiva sirva para a libertação e não para a servidão dos homens”. Essas memórias, muitas vezes, trazem a ancestralidade de histórias de tempo de escravização, das lutas, das negociações das grandes lideranças locais que comandaram os primeiros quilombos da região do Sapê do Norte. Foi por meio das narrativas que as/os professoras/os apontaram o histórico regional e toda teia de relações sociais. São falas e vozes que se misturam, presente e passado para se construir o futuro, forjados na resistência, conforme apontamentos a seguir.

\section{As narrativas e memórias das/os professoras/es e lideranças quilombolas na corrente contra hegemônica}

Trabalhar com as narrativas desse grupo na pesquisa-ação oportunizou-nos a escuta de diferentes vozes. Destacamos ainda que foram as narrativas que proporcionaram uma amplitude de compreensão do estudo proposto e, como destaca Benjamim (1994), a narrativa apresenta uma conexão com a experiência. Benjamim afirma que o narrador retira o que ele conta da experiência, de sua própria experiência ou da relatada por outros e assim incorpora, por sua vez, as coisas narradas às experiências de seus ouvintes.

Foi acreditando nesse pensamento filosófico que as narrativas foram valorizadas nesse estudo já que tivemos a finalidade de trazer saberes e conhecimentos outros na formação de professoras/es e lideranças. Quando se fala de formação de professoras/es, implicitamente, estamos direcionando olhares para as práticas docentes, pois a formação pressupõe aprendizados e conhecimentos atrelados às práticas docentes. Dessa forma, conhecimentos relacionados ao modo dominante de se produzir e validar as ciências influenciam na negação Revista RBBA $\mid$ Revista Binacional Brasil Argentina 
SAPÊ DO NORTE-CONCEIÇÃO DA BARRA-ES: O QUE NOS DIZEM?

dos conhecimentos e saberes das minorias. Parafraseando Santos (2007), a invisibilidade é a negação "dos saberes outros".

Entre as estratégias criadas na formação estava a de subsidiar o grupo no desenvolvimento de projetos pedagógicos dentro de suas comunidades partindo das problemáticas percebidas por cada um/a. Desta forma, muitas ações foram desenvolvidas e foi possível visualizar que os diálogos formativos estavam retornando para as comunidades em forma de educação escolar ou não-escolar. Nessa construção entrelaçada, percebemos que o grupo sempre apresentava problemáticas envolvendo "ausências" e como esses conhecimentos negados poderiam fazer a diferença nas comunidades se fossem valorizados nas formações de professoras/es de modo a impactar os seus fazeres. Como aponta a professora Sidineide, ao destacar a intencionalidade do projeto desenvolvido na Comunidade quilombola de Santana. Ela relata que:

O projeto foi pensado com a intenção de dialogar com os moradores mais antigos da Comunidade, levantar informações pertinentes às tradições culturais do nosso território, assim como a importância das plantas medicinais no preparo dos chás para curar as dores como erva-santa para dor de barriga, chá de tomatinho para dor de dente; banho de raiz de taririquim para combater febre e gripe, banho de folhas-de-boldo para mau-olhado. (Prof ${ }^{a}$. Sidineide, Conceição da Barra-2019)

Se a professora citada selecionou esses saberes para o projeto desenvolvido na comunidade, presume-se que a problemática alavancada se fazia pertinente à inserção desses conhecimentos nas ações pedagógicas. Esse olhar contra hegemônico é de grande relevância para romper com o paradigma dominante ditado para as minorias, ou seja, quais conhecimentos são válidos ou invalidados. Santos $(2007 ; 2010 b)$, baseando-se na crítica da sociologia das ausências, destaca alguns caminhos para se pensar os saberes negados pela ciência hegemônica. Ele ressalta que essa compreensão das ciências sociais age na lógica de selecionar determinados conhecimentos e, assim, acaba por excluir os saberes e conhecimentos dos subalternizados/colonizados.

Logo, é de nosso interesse buscar a reflexão de como visualizamos esses saberes outros nos espaços formativos de intervenção social. Ao apresentar sua comunidade, a professora Sidineide aponta os saberes e conhecimentos da comunidade quilombola de Santana. Sua narrativa nos aproxima das experiências e "saberes outros" da comunidade de Santana. Ela relata:

Revista RBBA Revista Binacional Brasil Argentina 
SAPÊ DO NORTE-CONCEIÇÃO DA BARRA-ES: O QUE NOS DIZEM?

As plantas medicinais são de grande relevância para os povos do território do Sapê do Norte, principalmente na Comunidade Santana, pois temos grandes defensores da medicina popular como: Maria Amélia que possui, em seu quintal, uma horta com plantas medicinais capazes de curar alguns males como: dor de cabeça, dor de barriga, mau-olhado, dor na coluna. As plantas são terramicina, hortelã, erva-cidreira, erva-santa, tipi e outros. A senhora Jurema Thomaz, também conhecida por Juju, é grande conhecedora da medicina popular e prepara pomadas, ensina chás e faz garrafadas para curar bronquite, enxaqueca, articulações, problemas nos rins, asma etc. E o Sr. Biti ensina remédios caseiros para diabetes, colesterol, febre, dor de cabeça etc... (Sidineide-2019)

Certamente, pensando no desenho da crítica colonial, para nós, os "saberes outros" citados nesse texto são, diretamente, conhecimentos e saberes quilombolas. Sabemos também que diversas temáticas que envolvem as relações étnico-raciais são neutralizadas ou invisibilizadas nas formações de professores e. consequentemente, nos diálogos curriculares. A professora Soraya da comunidade de Coxi apresentou a seguinte justificativa para o projeto de intervenção social desenvolvido em sua comunidade. Segundo ela:

Ao observar os alunos em seu cotidiano escolar, percebeu-se que a maioria de comunidade quilombola tem receio de onde vem. A impressão que eles demonstram é de vergonha, é preciso desmistificar essa ideia e mostrar aos alunos sua valorização e a contribuição histórica que exercem na sociedade e seus direitos dentro dela. (Soraya, 2019)

Percebe-se que o relato apresentado pela professora aponta o comportamento de seus estudantes frente às questões raciais, bem como a dificuldade de se perceberem como quilombolas. Isso faz parte dos resultados do jogo do racismo estrutural que apaga as culturas dessa população gerando o complexo de inferioridade e essa recusa. Eis um grande desafio nessas comunidades. A professora e liderança, ainda, aponta a problemática encontrada que a mobilizou para a escrita e desenvolvimento do projeto pedagógico. Em todo o texto escrito, ela demonstra os impactos negativos causados por ideias racistas difundidas na comunidade. Ideais que desqualificam o jeito de ser e viver quilombola. Afirma que "É de suma importância valorizar nos alunos sua ancestralidade e, posteriormente, sua origem. A partir de aí desconstruir a ideia de que somos de um lugar ruim, de uma cultura suja, de raízes podres. (Professora e liderança Soraya-2019).

O que a professora aponta pode ser explicado em linhas breves, no viés do que Carneiro (2005) traz em sua pesquisa, intitulada: "A construção do outro como não-ser como Fundamento do ser" na qual destrincha sobre a morte do sujeito negro. Apresenta um estudo 
profundo de dispositivo e raça, racialidade e educação, biopoder e raça, raça e epistemicídio, resistências e educação. Evidencia que, na natureza da dominação, uma fórmula banal é aplicada por meio da "negação da identidade do outro, dos seus valores de cultura e de sua humanidade" (CARNEIRO, 2015, p.173). Gomes e Silva (2006) indicam que, ao articular a formação de professores/as, os saberes, valores, histórias de vida e culturas nos deparamos com algo complexo que ultrapassa as questões de um currículo.

As pesquisadoras apontam as reflexões e os desafios dos estudos e pesquisas na área de formação de professores/as que articulem as temáticas "tão caras à escola e aos movimentos sociais". Destacam, por exemplo, as temáticas da diversidade étnico-cultural que são deixadas às margens do currículo e das formações. Ressaltam que as pesquisas têm sido crescentes e os/as professores/as têm mostrado interesse em formações que trazem o desenvolvimento profissional aliado às histórias de vida. $\mathrm{O}$ que elas categorizam como a busca de "novas mentalidades". E foi isso que as/os participantes dessa pesquisa nos mostraram desde o primeiro encontro formativo, pois apontaram que queriam formação e disseram como, quando, onde e para quê. Essas questões só se tornaram visíveis a nós porque tivemos decência e ética na pesquisa valorizando a escuta e a construção coletiva das ações da intervenção social.

Cabe ressaltar que as vozes apresentadas nesse artigo apontaram como a educação- não escolar tem alicerce nos conhecimentos e saberes das comunidades. Fontes que as/os forjaram como professoras/es e lideranças. Maioria mulheres, essas professoras também são lideranças que estão na linha de frente das lutas nos territórios e são as primeiras a sofrerem o racismo advindo das estruturas sociais. Possuem, em seus históricos de vida, a vivência do racismo, inclusive relatam essas marcas do tempo de escola, como apontam as memórias da professora Geanis Cosme. Ela cita os elementos curriculares (da época de escola) que não tratavam das questões étnico-raciais e também enfatiza os movimentos sociais que a educaram para a luta antirracista. Ela destaca:

(...) então fui estudar na cidade e realmente era tudo diferente. Passei por várias situações, enfrentei preconceito dentro da sala de aula pelos professores e até pelos outros alunos que se achavam mais inteligentes porque moravam na cidade. Mas uma coisa muito importante aprendi em casa com minha mãe que nunca abaixasse a cabeça para ninguém porque ninguém é melhor que ninguém, independentemente de qualquer coisa. A questão racial sempre foi bem clara na minha cabeça, porque minha mãe é minha base até hoje, sempre nos alertou sobre o assunto. Na escola do campo, se discutia a questão racial, mas era bem vago, mas no dia 20 de novembro que é o dia da consciência negra, e na escola da cidade não era diferente, acredito eu que na grade 
SAPÊ DO NORTE-CONCEIÇÃO DA BARRA-ES: O QUE NOS DIZEM?

curricular naquela época era pouco discutida a temática sobre preconceito racial principalmente na sala de aula. Quando comecei a frequentar de fato os movimentos sociais Quilombolas, MST, MPA e demais Organizações nãogovernamentais que esclareceram muito, mas minhas ideias a partir daí pude lutar pelos meus direitos e do meu povo. (Professora e liderança Geanis Cosme - 2019)

Gomes (2006) reafirma que os movimentos sociais sempre foram e estiveram mais sensíveis que a escola e estado brasileiro no que se refere às questões da diversidade. Destaca que a atuação de movimentos de mulheres, dos negros, dos povos indígenas, dos sem-terra trouxe "objetividade" à questão da diversidade. Outras professoras, assim como a Geanis, nos apontaram a importância de estar nos movimentos sociais tomando posição como lideranças para o benefício das comunidades onde moram e trabalham.

A partir de narrativas em que as/os participantes registraram para nós suas memórias, as lutas das comunidades, de suas ancestralidades, conhecimentos outros e demais saberes necessários e de grande relevância no espaço tempo formativo, foi que se concretizou a formação a qual se concentrou no auditório da Secretaria de Educação do município de Conceição da Barra. Foram realizados 10 encontros presenciais, aos sábados, com carga de 80h presenciais. Nesse locus formativo de pesquisa, foi possível acessar essas narrativas e participar desse movimento de escuta sensível. Isso nos faz acreditar na possibilidade de valorização das memórias coletivas dos indivíduos. Ressaltamos ainda que, durante a reunião dessas vozes no espaço de formação, visualizamos um movimento contra hegemônico no qual se busca e se forja a resistência para não deixar cair no silenciamento as tantas histórias que compõem e compuseram os territórios representados, pois creditamos que buscar essas memórias é buscar conhecimento e conhecimento é poder.

Andrade (2007) aponta que o estudo do currículo vivido, nas comunidades quilombolas, nas escolas e além da escola, só ganha visibilidade quando fazemos a escuta e exploração das narrativas dos sujeitos que ali se encontram. E, numa relação de diálogo, é preciso tentar compreender como são construídos esses conhecimentos e como eles são incluídos nas lutas por emancipação. Desse modo, as questões referentes às diversidades étnico-culturais e às questões quilombolas não ficam reconhecidas apenas como tema, mas como elementos que precisam ser articulados à formação de professores/as juntamente às práticas educativas escolares e não escolares, cabendo, ainda, o cuidado de não transformar as questões em apenas metodologias e técnicas de ensino ditas como "diferentes", mas pensar em processos educativos 
SAPÊ DO NORTE-CONCEIÇÃO DA BARRA-ES: O QUE NOS DIZEM?

que compreendam as relações sociais, culturais e políticas das comunidades dentro da sociedade.

\section{Considerações do movimento da pesquisa-ação}

Por meio das narrativas das/os professoras/es e lideranças quilombolas, foi possível fazer algumas considerações no que tange à formação e professoras/es quilombolas. Nota-se que ainda temos muito o que fazer e lutar. Essa luta é possível entrelaçando saberes e construindo redes de resistência. Apresentamos alguns pontos a destacar que apontam algumas reflexões necessárias para se pensar a formação de professoras/es quilombolas, pois as narrativas do grupo participante do processo formativo foram analisadas e contextualizadas mostrando: Necessidade de implementação de formação para professoras/es da educação quilombola, sendo essa pensada no coletivo junto aos profissionais e comunidades quilombolas, tendo em vista que o grupo se mostra no compromisso social não de "cruzar os braços", principalmente as lideranças que, mesmo sem espaços formativos que atendam suas especificidades, ainda buscam direções pedagógicas na valorização da identidade quilombola, dos territórios, das memórias e histórias ancestrais. Essa reflexão se baseia nas escutas que apontaram a invisibilidade ou inexistência de formações para educação quilombola da região da pesquisa. Conforme Gomes (2003, p.169), a formação de professores/as que visa à diversidade deveria considerar:

Que temas os/as professores/as gostariam de discutir e de debater no seu percurso de formação e no dia a dia da sala de aula? E que temáticas sociais e culturais são omitidas, não são discutidas ou simplesmente não são consideradas importantes para a sua formação profissional e para o processo educacional dos seus alunos? Será que a questão racial está incluída nessas temáticas omitidas ou silenciadas?

Compreendemos que são muitos desafios apontados pelos/as participantes e que o modo de se pensar a formação de professoras/es quilombolas precisa partir da construção coletiva, de escutas sensíveis e qualificadas dos sujeitos imbricados na educação quilombola, sujeitos que, na maioria, vivem as comunidades, sabem do que os territórios precisam, fazem parte do texto e contexto histórico das comunidades, são agentes pedagógicos da educação escolar e são também “agentes-pontes" da educação não-escolar. Gomes (2003, p.170) reforça que:

Revista RBBA Revista Binacional Brasil Argentina 
(...) existem diferentes e diversas formas e modelos de educação, e que a escola não é o lugar privilegiado onde ela acontece e nem o professor é o único responsável pela sua prática. Essa reflexão é importante para se pensar os processos educativos, quer sejam escolares ou não-escolares. Muitas vezes, as práticas educativas que acontecem paralelamente à educação escolar, desenvolvidas por grupos culturais, ONG's, movimentos sociais e grupos juvenis precisam ser considerados pelos educadores escolares como legítimas e formadoras. Elas também precisam ser estudadas nos processos de formação de professores

Destaca-se, ainda, que a formação de professores/as "[...] diz respeito à identidade do professor e da professora, enquanto agentes pedagógicos e políticos com direitos e deveres não só de executar políticas educacionais, mas de participar de sua concepção e avaliação". (GOMES; SILVA, 2006, p.17)

Os caminhos reflexivos para a construção da formação de professoras/es quilombolas a partir da construção coletiva das comunidades, professoras/es, lideranças e Secretaria de Educação são possíveis, pois as narrativas do quilombo contam sobre suas identificações étnicas, sobre conhecimentos, culturas e saberes das comunidades, sobre as potências políticas marcadas, em especial nas vidas das professoras, das lutas históricas contra opressão. Esses sujeitos apontam a reflexão de como acontecem "as burlas" que essa categoria é capaz de fazer para construir uma educação diferenciada.

Para implementar as leis 10.639/03 e 11.645/08 bem como as Diretrizes Curriculares Nacionais para a Educação Escolar Quilombola na Educação Básica, faz-se necessária atitude compromissada com a Educação Pública Municipal, incluindo no plano anual de formações de professoras/es todas as demandas das leis, em especial das Diretrizes Curriculares da Educação Quilombola, das propostas das comunidades e movimentos sociais para que, assim, possam contemplar as questões da educação quilombola não como apêndice em outras formações, mas respeitando suas especificidades e demandas que surgem no chão e ares das escolas e comunidades quilombolas. 


\section{REFERÊNCIAS}

ANDRADE, P.G.R. A Educação do negro na comunidade de Monte Alegre - ES em suas práticas de desinvibilização da cultura popular negra. 2007. Dissertação (Mestrado em Educação) - Universidade Federal do Espírito Santo, Vitória, 2007. 192p.

ANDRADE. P.G.R. Olhares sobre jongos e caxambus: Processos educativos nas práticas religiosas afro-brasileiras. Tese (Doutorado em Educação) - Universidade Federal do Espírito Santo, 2013.

ARAÚJO, N.S.M, A., P.G.R, VIDIGAL, S. R.; CASSIANO, G. Modos de ser e sentir: entrelaçando narrativas das crianças e professoras quilombolas. Argumentos Pró-Educação, v. 5, p. 90-120, 2020.

ASSOCIAÇÃO BRASILEIRA DE ANTROPOLOGIA - ABA. Documento do Grupo de Trabalho sobre Comunidades Negras Rurais (Rio de Janeiro, 17-18 de outubro de 1994). Boletim Informativo NUER - Núcleo de Estudos sobre Identidade e Relações Interétnicas / Fundação Cultural Palmares - v. 1, Florianópolis: UFSC, 1997, p. 81-82.

BARBIER, R. A escuta sensível na abordagem transversal. In BARBOSA, Joaquim (Coord). In: Multirreferencialidade nas ciências e na educação. São Carlos: EdUFSCar, 1998. p.168-199.

A pesquisa-ação na instituição educativa. Trad. Estela dos Santos Abreu. Rio de Janeiro: Jorge Zahar, 1985.

BENJAMIN, W. Obras Escolhidas Volume - I. Magia e técnica, arte e política: ensaios sobre literatura e história da cultura. Walter Benjamin. tradução Sérgio Paulo Rouanet. $7^{\circ}$ edição. São Paulo: Brasiliense. 2012.

BRASIL. Resolução $\mathbf{n}^{\mathbf{0}} \mathbf{8}$, de 20 de novembro de 2012. Define as Diretrizes Curriculares Nacionais da Educação Escolar quilombola na Educação Básica. Brasil. 2017

. [Constituição (1988)]. Constituição da República Federativa do Brasil de 1988. Brasília, DF: Presidência da República, [1988]. Disponível em: http://www.planalto.gov.br/ccivil_03/Constituicao/Constituiçao.htm. Acesso em: 28 de outubro de 2018.

Lei no. 10.639, de 9 de janeiro de 2003. Altera a Lei no 9.394, de 20 de dezembro de 1996. DF: Presidência da República, [2003]. Disponível em: http://www.planalto.gov.br/ccivil_03/leis/2003/110.639.htm. Acessado em: 20 de out. 2018.

Lei $\mathbf{n}^{0}$ 12.288, de 20 de julho de 2010. Institui o Estatuto da igualdade racial. DF: Presidência da República, [2010]. Disponível em: http://www.planalto.gov.br/ccivil_03/_ato2007-2010/2010/lei/112288.htm. Acessado em: 10 nov 2018.

. Lei $\mathrm{n}^{\mathbf{0}}$. 5.692, de 11 de agosto de 1971. Fixa Diretrizes e Bases para o ensino de $1^{\circ} \mathrm{e}$ 2 graus, e dá outras providências. Disponível em: http://www.planalto.gov.br/ccivil_03/leis/15692.htm. Acessado em: 2 nov 2018. 
CARRIL, L. F. B. Os desafios da Educação quilombola no Brasil: O território como contexto e texto. Revista Brasileira de Educação. Vol. 22. № 69.2017. p.540-564.

CARNEIRO A. S. A Construção do Outro como Não-Ser como fundamento do Ser. Tese (Doutorado em Educação) - Universidade de São Paulo, São Paulo, 2005.

DIONNE, H. A pesquisa-Ação para o desenvolvimento local. Vol. 16. Trad. Michel Thiollent. Brasília, D.F. Ed: Liber Livro, 2007.

FANON, Frantz. Peau noire, masques blancs (Pele negra, máscaras brancas). Editora da Universidade Federal da Bahia, 2008.

FERREIRA, S. R. B. Da fartura à escassez: a agroindústria de celulose e o fim dos territórios comunais no Extremo Norte do Espírito Santo. 2002. Dissertação (Mestrado em Geografia Humana) - Universidade de São Paulo, São Paulo, 2002.

GOMES, N. L. Alguns termos e conceitos presentes no debate sobre relações raciais no Brasil: uma breve discussão. In: BRASIL. Educação Antirracista: caminhos abertos pela Lei Federal No 10.639/03. Brasília, MEC, Secretaria de Educação Continuada e Alfabetização e Diversidade, 2005. p. 39 - 62.

GOMES, N.L. Educação e Relações raciais: Refletindo sobre Algumas Estratégias de Atuação. In: MUNANGA, Kabengele (Org.). Superando o racismo na escola. Brasília: Ministério da Educação, Secretaria de Educação Continuada, Alfabetização e Diversidade, 2005.

GOMES, N. L. O Movimento Negro educador: saberes construídos nas lutas por emancipação. São Paulo: Editora Vozes, 2017.

GOMES, N.L, SILVA, P.B.G e. Experiências étnico-culturais para formação de professores. 2. ed- Belo Horizonte. Autêntica, 2006.

GOMES, N. L. Educação, identidade negra e formação de professores/as: um olhar sobre o corpo negro e o cabelo crespo. Educação e Pesquisa, São Paulo, v. 29, n. 1, p. 167-182, jan./jun. 2003

GONÇALVES, L. A. O, E. SILVA, P. B. G e. Movimento negro e educação. Revista Scielo. Set/Out/Nov/Dez, No 15.p.134-158. 2000.

GUIMARÃES. A. A; OLIVEIRA. O.M. Jongueiros e Caxambuzeiros no Espírito Santo pesquisa, extensão e políticas de salvaguarda do patrimônio cultural. V seminário internacional - políticas culturais - 7 a 9 de maio/2014. Setor de políticas culturais - fundação casa de Rui Barbosa - Rio de Janeiro - Brasil.

LE GOFF, J. História e memória / Jacques Le Goff; tradução Bernardo Leitão [et al.]. Campinas, SP. Editora da UNICAMP,1990. 
LEITE, I. B. Os quilombos no Brasil: questões conceituais e normativas. Etnográfica, Lisboa, v. IV, n. 2, p. 333-354, 2000.

Quilombos e quilombolas: cidadania ou folclorização? Quilombos e quilombolas. Horizontes Antropológicos, Porto Alegre, ano 5, n. 10, p. 123-149,1999.

MUNANGA, K. Origem e histórico do quilombo em África. In: MOURA, Clóvis. Os quilombos na dinâmica social do Brasil. Maceió: EDUFAL, 2001. p. 21-31.

OLIVEIRA, O. M de. Comunidades quilombolas no Estado do Espírito Santo: Conflitos sociais, consciência étnica e patrimônio cultural. RURIS, v. 5, n. 2, p. 141-171, 2011.

SANTOS, B. S. Para além do pensamento abissal: das linhas globais a uma ecologia dos saberes. In SANTOS, B. S.; MENESES, M. P. Epistemologias do Sul. São Paulo: Cortez, 2010b, p. 31-83.

Na oficina do sociólogo artesão. Aulas 2011-2016. São Paulo. Ed. Cortez. 2018.

Renovar a teoria crítica e reinventar a emancipação social/ tradução Mouzar Benedito. Ed. Boitempo. São Paulo.2007.

\section{Notas}

${ }^{i}$ No ano de 2012, o Programa de Pesquisa e Extensão da Universidade Federal do Espírito Santo (UFES),com apoio do Instituto de Patrimônio Histórico e Artístico Nacional (IPHAN) e a Secretaria de Estado da Cultura do Espírito Santo (Secult), desenvolveu duas oficinas de mobilização e organização comunitária para as regiões do sul e norte do Estado do Espírito Santo,com o objetivo de estudar e estimular a auto-organização dos grupos, memórias e patrimônio cultural das comunidades jongueiras do Espírito Santo e elaborar subsídios que fomentem a construção das políticas públicas de apoio a essas comunidades. Nessas oficinas, os grupos organizaram um documento intitulado: "CARTA DE PROPOSTAS DOS GRUPOS DE JONGOS E CAXAMBUS DO ESPÍRITO SANTO PARA A SALVAGUARDA DE SEU PATRIMÔNIO CULTURAL" composto por demandas de políticas públicas de salvaguardas de suas culturas e tradições. Entre essas demandas, a formação de professoras/es para assegurar as leis 10.639/03 e 11.645/08.

${ }^{\mathrm{i}}$ A teorias raciais foram importadas da Europa e difundidas no Brasil no século XIX, justificando interesses políticos e sociais das elites que no pós-escravização. O Brasil importou essas teorias do francês Arthur Gorbineau, que apresentava em pesquisas e no seu ensaio sobre "desigualdades das raças" (1882) afirmava a superioridade da "raça branca", reforçando que as raças eram desiguais baseado na biologia. 